\title{
Impact of concomitant obstructive sleep apnea on pulmonary involvement and main pulmonary artery diameter in adults with scleroderma
}

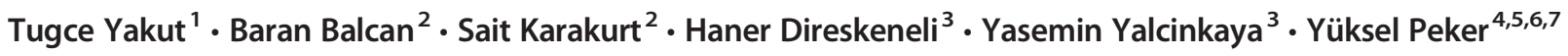

Received: 21 December 2019 /Revised: 26 February 2020 / Accepted: 10 March 2020 / Published online: 13 April 2020

(C) The Author(s) 2020

\begin{abstract}
Purpose Pulmonary involvement is common in adults with scleroderma. The effect of concomitant obstructive sleep apnea (OSA) on risk for pulmonary hypertension in scleroderma is unknown. An enlarged main pulmonary artery diameter (mPAD) derived from chest computer tomography (CT) is a useful predictor of pulmonary hypertension. We addressed the effect of OSA on pulmonary involvement and enlarged mPAD in adults with scleroderma.

Methods All participants underwent pulmonary function testing, carbon monoxide diffusion capacity, chest CT, and overnight sleep recording with home sleep apnea testing. OSA diagnosis was based on an apnea-hypopnea index (AHI) $\geq 15 / \mathrm{h}$. Oxygen desaturation index (ODI) was also recorded. Scleroderma involvement of the lungs was defined as the Warrick score $\geq 7$ based on the CT findings. Enlarged mPAD was defined as an $\mathrm{mPAD} \geq 29 \mathrm{~mm}$ in men and $\geq 27 \mathrm{~mm}$ in women.

Results After exclusions, 62 patients (58 women) were included. OSA was found among 20 (32\%), 17/42 (38\%) in the limited cutaneous type, and $3 / 20(15 \%)$ in the diffuse cutaneous type $(p=0.08)$. Scleroderma involvement of the lungs was observed in 40 participants (65\% in OSA vs 64\% in no-OSA; n.s.). Enlarged mPAD was measured in 16 participants, 10 of $20(50 \%)$ in the OSA group and 6 of $17(14 \%)$ in the no-OSA group $(p=0.003$ ). OSA was associated with enlarged mPAD (odds ratio 4.7, 95\% confidence interval 1.1-20.9; $p=0.042$ ) independent of age, body mass index, and pulmonary involvement. There was a linear relationship between mPAD and AHI $(r=0.37 ; p=0.003)$ as well as ODI $(r=0.41 ; p<0.001)$.

Conclusions In this cohort, OSA was associated with risk for pulmonary hypertension independent of pulmonary involvement. These findings suggest that assessing the effect of therapy for concomitant OSA in patients with scleroderma is warranted.

Trial registration NCT 02740569
\end{abstract}

Keywords Obstructive sleep apnea $\cdot$ Scleroderma $\cdot$ Pulmonary involvement $\cdot$ Pulmonary hypertension

\section{Introduction}

Scleroderma is an autoimmune, inflammatory, progressive, and multi-systemic disease, which is characterized with fibrosis in the skin and the connective tissue of the viscera.

Yüksel Peker

yuksel.peker@lungall.gu.se

1 Department of Allergology and Immunology, Süreyyapasa Chest Diseases and Chest Surgery Training \& Research Hospital, Istanbul, Turkey

2 Department of Pulmonary Medicine, Marmara University, School Medicine, Istanbul, Turkey

3 Department of Rheumatology, School of Medicine, Marmara University, Istanbul, Turkey
Scleroderma can affect the lungs, kidneys, gastrointestinal system, and heart [1]. When the lungs are affected, scleroderma is often progressive with high risk for morbidity and mortality [2]. Pulmonary involvement has been demonstrated among $70-90 \%$ of patients suffering from scleroderma [3].

4 Department of Pulmonary Medicine, School of Medicine, Koc University, Koc University Hospital, Davutpasa cad, No. 4, Zeytinburnu, TR-34010 Istanbul, Turkey

5 Department of Clinical Sciences, Respiratory Medicine and Allergology, Faculty of Medicine, Lund University, Lund, Sweden

6 Sahlgrenska Academy, University of Gothenburg, Sweden, Gothenburg, Sweden

7 Division of Pulmonary, Allergy, and Critical Care Medicine, University of Pittsburgh School of Medicine, Pittsburgh, PA, USA 
Obstructive sleep apnea (OSA) is characterized by repeated apnea and hypopnea episodes and disturbances in arterial oxygen saturation [4]. It has been suggested that OSA is associated with local or systemic inflammatory diseases [5]. Less is known regarding the association of OSA with scleroderma. In one study, addressing the occurrence of OSA in interstitial lung disease, scleroderma constituted a small subgroup of 18 patients among others [6]. To our best knowledge, occurrence of OSA solely in patients with scleroderma with or without pulmonary involvement has yet not been defined. It is also unclear to which extent a concomitant OSA is associated with pulmonary hypertension in scleroderma patients.

Pulmonary hypertension is defined as a mean pulmonary artery pressure (mPAP) over $20 \mathrm{mmHg}$ based on right heart catheterization [7]. However, right heart catheterization is invasive and demands exposure to contrast and ionizing radiation, and does not provide morphologic information [8]. Echocardiography is commonly used to screen suspected pulmonary hypertension patients [9], but the diagnostic accuracy of echocardiography is known to be dependent on several factors, such as body habitus, evident tricuspid regurgitation, heart rate, and the experiences of operators, which limit its clinical function [10]. Enlarged main pulmonary artery diameter (mPAD) $\geq 29 \mathrm{~mm}$ in men, and $\geq 27 \mathrm{~mm}$ in women, respectively, derived from chest computer tomography (CT), is suggested to be a useful predictor of pulmonary hypertension [11].

In the current study, we aimed to address occurrence of OSA in patients with scleroderma, and its possible association with CT-determined pulmonary involvement and enlarged mPAD.

\section{Methods}

\section{Study design and patients}

This cross-sectional cohort study was conducted at the Marmara University Pendik Teaching and Education Hospital, Istanbul, between 01 April and 01 October 2016. Patients with a known scleroderma diagnosis attending to the Departments of Rheumatology and/or Pulmonary Medicine, without any concomitant psychiatric or neurologic disease, were invited to participate. The study protocol conforms to the ethical guidelines of the 1975 Declaration of Helsinki as reflected in a priori approval by the Ethics Committee of the Medical Faculty of the Marmara University, Istanbul (approval no.: 09.2016.208). All patients provided written informed consent. The trial was registered with the ClinicalTrials.gov (NCT 02740569).

\section{Definition of baseline clinical characteristics}

Anthropometrics, smoking habits, and past medical history for the whole population were obtained from the medical records. Height, weight, and waist circumference were measured, and body mass index (BMI) was calculated according to the formula body weight divided by height squared, and obesity was defined as a BMI of at least $30 \mathrm{~kg} / \mathrm{m}^{2}$ [12]. Patients were classified as having limited cutaneous systemic sclerosis or diffuse cutaneous systemic sclerosis according to the criteria of Leroy et al., based on the extension of skin involvement [13]. Anti-nuclear antibody (ANA) was detected by using immunoflourescent assay (IFA) with a screening titer of 1:160 and above. The presence of anti-topoisomerase (antiSc170) and anti-centromere (ACA) were measured by using immunoblotting method - extractable nuclear antigen (ENA) panel antibodies. Information about concomitant diseases at baseline, including hypertension and diabetes, was based on self-reported and/or physician-diagnosed conditions. Ongoing medications were also obtained.

\section{Pulmonary function testing}

Pulmonary function including forced expiratory volume in $1 \mathrm{~s}$ $\left(\mathrm{FEV}_{1}\right)$, and forced vital capacity (FVC), was measured with MIR Spirolab II spirometry (Medical International Research, Rome, Italy), diffusing capacity of lung for carbon-monoxide $\left(\mathrm{DL}_{\mathrm{CO}}\right)$ in a body-plethysmograph (CareFusion Type MasterScreen PFT; Hoechberg, Germany), and a 6-min walking test (SMWT) was performed - in a $30-\mathrm{m}$ flat indoor corridor-and all results were evaluated according to the ATS guidelines [14-17].

\section{High-resolution computed tomography}

All patients underwent a high-resolution computed tomography (HRCT) at the Department of Radiology using Siemens SOMATOM Definition Flash (Erlangen, Germany) scans. A new HRCT was performed, if the existing measurement was older than 6 months. The scans of the chest were obtained with patients in supine position and with lungs at end-inspiration. The area of the scans ranged from the lung apices to bases, with $0.6-\mathrm{mm}$ collimation, 1 - to $2-\mathrm{mm}$ slice thickness at 0.5 $\mathrm{mm}$ increments. Five crucial abnormalities were distinguished and their severity was assessed with the Warrick score [18]: ground glass opacities (score 1), irregularities in the pleural margins (score 2), septal and subpleural lines (score 3), honeycomb lung (score 4), and subpleural cysts (score 5). An additional extent score was added to each severity score, i.e., abnormality involving 1-3 segments (extent score 1), 4-9 segments (extent score 2), and more than 9 segments (extent score 3), respectively. A total score range was $0-30$. Pulmonary involvement was defined as a Warrick score of at 
least 7 on the HRCT [19]. Explicitly, the transverse axial diameter of the mPA and the ascending aorta at the level of the bifurcation of the right pulmonary artery were measured [11]. The ratio of mPAD to ascending aorta diameter (ratio PA) was also calculated. All findings were scored by the same experienced pulmonologist (S.K.) blinded to the patients' clinical characteristics and results of the pulmonary function tests and sleep recordings.

\section{Epworth Sleepiness Scale}

Subjective sleepiness was evaluated using the Turkish version of the Epworth Sleepiness Scale (ESS) questionnaire, which is the most widely used index in sleep clinics [20,21]. The ESS consists of 8 questions for assessing the chance of dozing off under 8 situations in the past month. Each item is scored from 0 to 3 ( 0 , would never doze; 1 , slight chance of dozing; 2 , moderate change of dozing; 3 , high chance of dozing). The ESS score ranges from 0 to 24. Excessive daytime sleepiness (EDS) was defined as the ESS score of at least 11 [22].

\section{Home sleep apnea testing}

The portable, limited sleep study was performed with a home sleep apnea testing (HSAT) device (NOX-T3; Nox Medical Inc., Reykjavik, Iceland) and consisted of a nasal pressure detector using a nasal cannula/pressure transducer system, thoracoabdominal movement detection through two respiratory inductance plethysmography belts, and a finger pulse oximeter detecting heart rate and oxyhemoglobin saturation $\left(\mathrm{SpO}_{2}\right)$ as well as body position and movement detection. Moreover, snoring was recorded by a built-in microphone in the NOX-T3 device which provides the opportunity to play the audio along with the other recorded signals during manual scoring of the events. The patient's sleep time was estimated on the basis of self-reporting as well as the pattern of body movement during the study. Patients with an estimated sleep time of less than $4 \mathrm{~h}$ were offered a new HSAT. Apnea was defined as an almost complete ( $\geq 90 \%)$ cessation of airflow, and hypopnea was defined as a reduction in nasal pressure amplitude of $\geq 30 \%$ and/or thoracoabdominal movement $\geq$ $30 \%$ for $\geq 10 \mathrm{~s}$ if there was a significant oxyhemoglobin desaturation (decrease by at least 3\% from the immediately preceding baseline value) according to the latest recommendations of the American Academy of Sleep Medicine [23]. Moreover, total number of significant desaturations was scored, and the oxygen desaturation index (ODI) was calculated as the number of significant desaturations per hour of estimated sleep. Minimum $\mathrm{SpO}_{2}$ and time spent below $90 \%$ $\mathrm{SpO}_{2}(\mathrm{TS} 90 \%)$ values were also recorded. OSA was defined as an apnea-hypopnea index (AHI) $\geq 15$ events/h of the total estimated sleep time, based on the latest International Classification of Sleep Disorders -3[24], when OSA-related symptoms are absent. All HSATs were scored by the same physician (Y.P.), blinded to patient demographics, clinical characteristics, and results of the pulmonary function tests and HRCTs.

\section{Statistical analysis}

Descriptive statistics are given as means \pm SD and categorical variables as numbers (percentages). Comparison of categorical variables was done using the chi-squared test, and when appropriate, the Fisher exact test. Differences in means between groups were analyzed by Student $t$ test, and when there was a skewed distribution, the Mann-Whitney $U$ test was used. Pearson correlation coefficients were calculated for analyzing the associations between continuous variables of the pulmonary function tests, Warrick scores, mPAD values, and sleep recordings. A logistic regression analysis was used to test the association between OSA and pulmonary involvement as well as enlarged mPAD. All variables that were significant in the bivariate analyses were subsequently included in the multivariate model, and odds ratios (ORs) with $95 \%$ confidence intervals $(\mathrm{CI})$ were calculated from the regression coefficients. All statistical tests were two-sided, and $p<0.05$ was considered statistically significant. Statistical analysis was performed using the Statistical Package for Social Sciences, version 25.0 for Windows ${ }^{\circledR}$ system (SPSS ${ }^{\circledR}$ Inc., Chicago, IL, USA).

\section{Results}

As shown in Fig. 1, 79 patients with scleroderma were eligible for the study. Two patients were not included due to comorbid psychiatric and neurological diagnosis, and 13 patients refused participation. Out of 64 patients undergoing HSAT, 2 were excluded due to technical failure and their unwillingness to repeat the sleep studies. Thus, 62 patients ( 43 with limited scleroderma, 19 with diffuse scleroderma; mean age $48 \pm$ 11 years (range 21-72 years)); 58 (93.5\%) female; mean BMI $26.7 \pm 5.0 \mathrm{~kg} / \mathrm{m}^{2}$ ) with HSAT results and available HRCT scans within the last 6 months, were included in the final analysis.

As shown in Table 1, patients with the diffuse cutaneous scleroderma type were dominantly anti-Scl70-positive and had more pulmonary involvement based on the Warrick score compared with the limited cutaneous scleroderma type, but mPAD values did not differ significantly. AHI and ODI values were significantly higher in the limited sclerosis type.

In the entire cohort, OSA was observed among 20 (32.3\%), $17(38.1 \%)$ in the limited cutaneous type and $3(15.0 \%)$ in the diffuse cutaneous type (Table 2). The participants with OSA were older and had higher BMI and waist circumference, and obesity and hypertension were more prevalent compared with 
Fig. 1 Flow chart of the study participants
79 consecutive Scleroderma patients were assessed for eligibility between April 2016 and October 2016

15 Were excluded

2 Had psychiatric and neurological disorders

13 Were not interested in the study

64 Underwent home sleep apnoea testing, and high resolution computed tomography

2 Were excluded due to technical failure and unwillingness to repeat the sleep study

62 Scleroderma participants met the inclusion criteria for the main study those in the no-OSA group. Though the ESS score tended to be higher among the patients with OSA, the average value was quite low, and the predefined cutoff value of excessive daytime sleepiness (ESS score $>10$ ) was observed among only 5 $(25 \%)$ of the OSA patients (n.s.). The duration of the scleroderma since diagnosis as well as ongoing medications and inflammatory markers did not differ significantly between the groups at the time of the sleep studies. By definition, $\mathrm{AHI}$ and ODI values were higher, and $\mathrm{SpO}_{2}$ drops were more severe in the OSA group (Table 2). Proportion of the patients with pulmonary involvement based on the HRCT findings was similar in the OSA group (65.0\%) compared with the patients without OSA (64.3\%). There were no significant differences between the groups regarding $\mathrm{FEV}_{1} \%, \mathrm{FVC} \%$, and $\mathrm{DL}_{\mathrm{CO}} \%$ values and 6-min walking test. Enlarged mPAD was found among 16 participants, of whom 10 (50.0\%) within the OSA group, and $6(14.3 \%)$ in the no-OSA group ( $p=0.003)$. The average mPAD as well as ascending aorta diameter were significantly higher in the OSA group while the ratio PA did not differ significantly (Table 2). The occurrence rate of enlarged mPAD was similar in the subgroup of patients with AHI $<15$ but $\geq 5$ (3 out of 23 ) compared with that among the patients with AHI $<5$ ( 3 out of 19 ).

In the logistic regression analysis, neither OSA nor the OSA indices (AHI, ODI, minimum $\mathrm{SpO}_{2}$, and TS90\%) were associated with the CT-determined pulmonary involvement (data not shown). None of the OSA indices was significantly correlated with the Warrick score while there was an inverse relationship between $\mathrm{TS} 90 \%$ and $\mathrm{DL}_{\mathrm{CO}} \%$ (Fig. 2), and this relationship was independent of age, BMI, and AHI ( $\beta$ coefficient $-0.39,95 \%$ confidence interval $[\mathrm{CI}]-0.31--0.05$; $p=0.007)$.

As shown in Table 3, BMI, OSA, and OSA severity indices were significantly associated with enlarged mPAD. In the multivariate model, OSA remained significant with a 4.7-fold risk for enlarged mPAD after adjustment for age, BMI, and CT-determined pulmonary involvement. Moreover, there was a significant linear correlation between mPAD and AHI as well as ODI (Fig. 3a, b).

\section{Discussion}

In the current study, OSA was associated with risk for pulmonary hypertension in scleroderma patients independent of pulmonary involvement, and there was a significant association between mPAD and OSA severity indices, AHI and ODI.

To our best knowledge, this study is the first to report occurrence of OSA in a consecutive scleroderma cohort, mainly with the limited cutaneous scleroderma type, and its association with enlarged mPAD. One previous questionnairebased study suggested that sleep disturbances were common in scleroderma patients, and this was mainly related with worsening of symptoms [25]. However, there were no OSAspecific questionnaires, and no sleep recordings were conducted in that report. The first study, in which the PSG parameters were presented, was conducted by Prado et al. who evaluated 27 scleroderma patients, and found no statistically significant difference between the assessed parameters including sleep stages but without any information about the respiratory events [26]. Other studies addressing the sleep disturbances in patients with scleroderma have suggested high occurrence of dyspnea, depression, serious reflux symptoms, pain, and itching during sleep, but without any information regarding OSA [25, 27].

In a previous study, addressing the relationship between OSA and interstitial lung disease, scleroderma constituted a subgroup of 18 adults among a total of 50 patients, and OSA 
Table 1 Characteristics of the study population based on the scleroderma type

\begin{tabular}{|c|c|c|c|}
\hline & $\begin{array}{l}\text { Limited cutaneous systemic } \\
\text { sclerosis }(n=43)\end{array}$ & $\begin{array}{l}\text { Diffuse cutaneous systemic } \\
\text { sclerosis }(n=19)\end{array}$ & $p$ value \\
\hline \multicolumn{4}{|l|}{ Variables } \\
\hline Age (years) & $49.7 \pm 12.3$ & $45.8 \pm 8.6$ & 0.222 \\
\hline Age $>60, n(\%)$ & $10(23.3)$ & $1(5.3)$ & 0.149 \\
\hline Female, $n(\%)$ & $42(97.7)$ & $16(84.2)$ & 0.082 \\
\hline BMI $\left(\mathrm{kg} / \mathrm{m}^{2}\right)$ & $27.4 \pm 4.6$ & $25.2 \pm 5.8$ & 0.116 \\
\hline Obesity, $n(\%)$ & $16(37.2)$ & $5(26.3)$ & 0.562 \\
\hline Current smoker, $n(\%)$ & $3(7.0)$ & $1(5.3)$ & 1 \\
\hline Hypertension, $n(\%)$ & $4(9.5)$ & $3(15.8)$ & 1 \\
\hline Diabetes mellitus, $n(\%)$ & $3(7.0)$ & $2(10.5)$ & 0.638 \\
\hline Cardiac disease, $n(\%)$ & $4(9.3)$ & $0(0.0)$ & 0.303 \\
\hline Disease duration (years) & $7.2 \pm 5.9$ & $9.3 \pm 7.0$ & 0.219 \\
\hline AHI (events/h) & $15.2 \pm 13.4$ & $7.6 \pm 7.0$ & 0.005 \\
\hline ODI (events/h) & $13.1 \pm 11.9$ & $6.7 \pm 6.0$ & 0.007 \\
\hline \multicolumn{4}{|l|}{ Laboratory findings } \\
\hline ANA titer $\geq 1 / 100, n(\%)^{*}$ & $38(90.5)$ & $18(100)$ & 0.175 \\
\hline Anti-Scl70-positive, $n(\%)^{*}$ & $6(14.3)$ & $14(77.8)$ & $<0.001$ \\
\hline ACA-positive, $n(\%)^{*}$ & $10(23.8)$ & $1(5.6)$ & 0.148 \\
\hline \multicolumn{4}{|c|}{$\mathrm{HRCT}$, spirometry, $\mathrm{DL}_{\mathrm{CO}}$ findings } \\
\hline Warrick score & $10.0 \pm 9.4$ & $17.1 \pm 8.9$ & 0.007 \\
\hline Warrick score $\geq 7, n(\%)$ & $24(55.8)$ & $16(84.2)$ & 0.031 \\
\hline $\mathrm{mPAD}(\mathrm{mm})$ & $25.6 \pm 5.5$ & $25.2 \pm 4.7$ & 0.741 \\
\hline Enlarged mPAD, $n(\%)$ & $13(30.2)$ & $3(15.8)$ & 0.347 \\
\hline $\mathrm{DL}_{\mathrm{CO}}(\%)^{* *}$ & $72.6 \pm 18.5$ & $63.1 \pm 22.7$ & 0.097 \\
\hline $\mathrm{DL}_{\mathrm{CO}}<80 \%, n(\%)^{* *}$ & $27(73.0)$ & $16(84.2)$ & 0.507 \\
\hline \multicolumn{4}{|l|}{ Medications } \\
\hline Corticosteroids, $n(\%)$ & $13(30.2)$ & $9(47.4)$ & 0.194 \\
\hline Methotrexate, $n(\%)$ & $5(11.6)$ & $4(21.1)$ & 0.941 \\
\hline Hydroxyklorokin, $n(\%)$ & $27(62.8)$ & $12(63.2)$ & 0.978 \\
\hline $\begin{array}{l}\text { Mycophenolate mofetil, } n \\
\text { (\%) }\end{array}$ & $5(11.6)$ & $10(52.6)$ & 0.001 \\
\hline Azathiopyrin, $n(\%)$ & $11(25.6)$ & $3(15.8)$ & 0.519 \\
\hline Leflunomide, $n(\%)$ & $2(4.7)$ & $0(0)$ & 1 \\
\hline
\end{tabular}

Values are mean \pm standard deviation (compared using independent student $t$ test) or number of patients (percentage) (compared using chi-squared test or Fisher's exact test). ACA, anti-centromere; AHI, apneahypopnea index; $A N A$, anti-nuclear antibody; Anti-Scl70, anti-topoisomerase 1 antibody; BMI, body mass index; $D L_{C O}$, diffusing capacity of lung for carbon-monoxide; $m P A D$, main pulmonary artery diameter; $O D I$, oxygen desaturation index. *Missing values in 2 patients. **Evaluated in 53 patients was diagnosed among 10 of 18 participants with scleroderma (55.5\%), applying an AHI cutoff value of 5 events/h according to the hypopnea criteria from 2007 [6]. Though not related with scleroderma, other studies have also addressed the relationship between parameters of OSA severity and interstitial lung disease with controversial results. In one study, PSG findings in idiopathic pulmonary fibrosis patients were evaluated, and the researchers found a significant correlation between $\mathrm{AHI}$ and $\mathrm{DL}_{\mathrm{CO}}$ [28], whereas another study failed to demonstrate such an association [29]. In our cohort, we found a significant inverse linear relationship between $\mathrm{DL}_{\mathrm{CO}}$ and TS90\%, as also reported by the abovementioned study [6].
Interestingly, scleroderma patients with OSA had higher TS90\% but also higher $\mathrm{DL}_{\mathrm{CO}}$ values than those without OSA. This discrepancy may be explained by possible within-group differences in the OSA subgroup. Indeed, the vast majority of the OSA patients had limited cutaneous systemic sclerosis, and thus, less $\mathrm{DL}_{\mathrm{CO}}$ reduction than those without OSA who had mainly the diffuse cutaneous form. The proportion of patients with $\mathrm{DL}_{\mathrm{CO}}<80 \%$ did not differ significantly between the groups, and the higher TS90\% among the OSA patients may also indicate that these drops were mainly due to the OSA per se, independent of concomitant pulmonary involvement in patients with scleroderma. 
Table 2 Study population based on the results of the home sleep apnea testing

\begin{tabular}{|c|c|c|c|}
\hline & $\begin{array}{l}\text { OSA }(-)(n=42)(\text { AHI } \\
<15 / h)\end{array}$ & $\begin{array}{l}\text { OSA }(+)(n=20)(\text { AHI } \\
\geq 15 / h)\end{array}$ & $p$ value \\
\hline \multicolumn{4}{|l|}{ Variables } \\
\hline Age (years) & $45.3 \pm 11.4$ & $55.14 \pm 7.6$ & 0.001 \\
\hline Age $>60, n(\%)$ & $5(14.3)$ & $6(25.0)$ & 0.302 \\
\hline Female, $n(\%)$ & $39(92.9)$ & $19(95.0)$ & 0.748 \\
\hline BMI $\left(\mathrm{kg} / \mathrm{m}^{2}\right)$ & $25.2 \pm 4.6$ & $29.9 \pm 4.4$ & $<0.001$ \\
\hline Obesity, $n(\%)$ & $10(23.8)$ & $11(55.0)$ & 0.015 \\
\hline Waist circumference $(\mathrm{cm})$ & $92.3 \pm 10.3$ & $106 \pm 9.5$ & $<0.001$ \\
\hline Current smoker, $n(\%)$ & $4(9.5)$ & $0(0)$ & 0.295 \\
\hline ESS score & $4.9 \pm 4.1$ & $7.6 \pm 5.7$ & 0.041 \\
\hline Hypertension, $n(\%)$ & $4(9.5)$ & $7(35.0)$ & 0.029 \\
\hline Diabetes mellitus, $n(\%)$ & $3(7.1)$ & $2(10.0)$ & 0.654 \\
\hline Cardiac disease, $n(\%)$ & $2(4.8)$ & $2(10.0)$ & 0.588 \\
\hline Disease duration (years) & $7.2 \pm 5.6$ & $8.9 \pm 7.3$ & 0.334 \\
\hline $\begin{array}{l}\text { Scleroderma type, diffuse } \\
\text { cutaneous, } n(\%) \text { limited } \\
\text { cutaneous }\end{array}$ & $17(38.1) 26(61.9)$ & $3(15.0) 17(85.0)$ & $\begin{array}{l}0.082 \\
0.082\end{array}$ \\
\hline \multicolumn{4}{|l|}{ HSAT findings } \\
\hline AHI (events/h) & $6.0 \pm 4.3$ & $27.2 \pm 11$ & $<0.001$ \\
\hline ODI (events/h) & $5.3 \pm 3.8$ & $23.4 \pm 10.4$ & $<0.001$ \\
\hline Mean $\mathrm{SpO}_{2}(\%)$ & $94.9 \pm 1.9$ & $93.1 \pm 1.7$ & $<0.001$ \\
\hline Minimum $\mathrm{SpO}_{2}(\%)$ & $85.3 \pm 6.8$ & $81.7 \pm 6.5$ & 0.053 \\
\hline $\mathrm{SpO}_{2}<\mathrm{T} 90(\%)$ & $3.3 \pm 7.8$ & $8.4 \pm 14$ & 0.070 \\
\hline Mean $\mathrm{SpO}_{2}$ drops $(\%)$ & $3.4 \pm 0.8$ & $4.4 \pm 0.8$ & $<0.001$ \\
\hline \multicolumn{4}{|c|}{$\mathrm{HRCT}$, spirometry, and $\mathrm{DL}_{\mathrm{CO}}$ findings } \\
\hline Warrick score & $12.1 \pm 9.9$ & $12.5 \pm 9.8$ & 0.882 \\
\hline Warrick score $\geq 7, n(\%)$ & $27(64.3)$ & $13(65.0)$ & 0.956 \\
\hline mPAD (mm) & $24.2 \pm 4.2$ & $27.8 \pm 5.3$ & 0.006 \\
\hline Enlarged mPAD, $n(\%)$ & $6(14.3)$ & $10(50.0)$ & 0.003 \\
\hline $\mathrm{AAD}(\mathrm{mm})$ & $30.3 \pm 4.9$ & $34.0 \pm 5.1$ & 0.007 \\
\hline Ratio PA & $0.8 \pm 0.1$ & $0.8 \pm 0.2$ & 0.590 \\
\hline $\mathrm{DL}_{\mathrm{CO}}(\%)^{*}$ & $67.2 \pm 18.4$ & $74.3 \pm 26.0$ & 0.267 \\
\hline $\mathrm{DL}_{\mathrm{CO}}<\% 80, n(\%)^{*}$ & $31(81.6)$ & $10(66.7)$ & 0.286 \\
\hline $\mathrm{FVC} / \mathrm{DL}_{\mathrm{CO}} *$ & $1.4 \pm 0.4$ & $1.2 \pm 0.5$ & 0.210 \\
\hline SMWT (m) & $316.7 \pm 74.5$ & $296.9 \pm 63.7$ & 0.310 \\
\hline
\end{tabular}

Values are mean \pm standard deviation (compared using independent student $t$ test) or number of patients (percentage) (compared using chi-squared test). AHI, apnea-hypopnea index; $A A D$, ascending aorta diameter; $D L_{C O}$, diffusing capacity of lung for carbon-monoxide; $E S S$, Epworth Sleepiness Scale; $F V C$, forced vital capacity; HRCT, high-resolution computed tomography; HSAT, home sleep apnea testing; $m P A D$, main pulmonary artery diameter; $O D I$, oxygen desaturation index; OSA, obstructive sleep apnea; Ratio PA, ratio of diameters mPA to AA; $S M W T$, 6-min walking test; $\mathrm{SpO}_{2}$, oxyhemoglobin saturation; T90, time spent below $90 \%$ oxyhemoglobin saturation. *Evaluated in 53 patients
To our best knowledge, there is yet no study addressing the association between OSA and pulmonary hypertension in patients with scleroderma. Previous reports from sleep clinic cohorts have suggested that nocturnal hypoxemia in moderate-to-severe OSA may contribute to vascular remodeling in pulmonary artery architecture, which may elevate pulmonary vascular resistance $[30,31]$. In one previous study, evaluating 155 patients with resistant pulmonary hypertension patients who underwent sleep study, there was a significant association between OSA severity and mPAD [32].

Pulmonary hypertension is defined as a mPAP over $20 \mathrm{mmHg}$ based on right heart catheterization [33]. However, right heart catheterization is invasive, demands exposure to contrast and ionizing radiation, and does not provide morphologic information [8]. Echocardiography is generally used to screen-suspected pulmonary hypertension patients [9], 


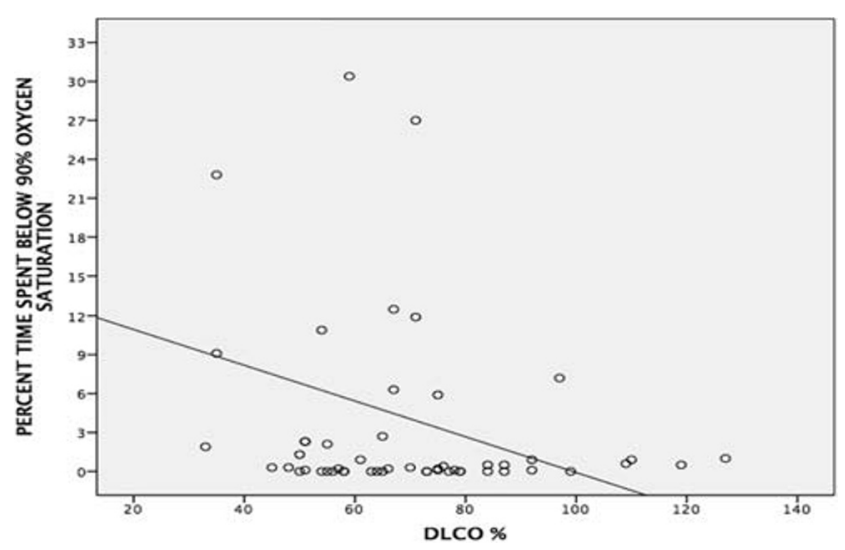

Fig. 2 Correlation between percent time spent below 90\% oxygen saturation and diffusing capacity of lung for carbon-monoxide $\left(\mathrm{DL}_{\mathrm{CO}} \%\right)$

but the diagnostic accuracy of echocardiography has been reported to depend on several factors, which limit its clinical application [10]. Enlarged mPAD derived from chest CT, based on the sex-specific cutoff values used in the current study, is suggested to be a useful predictor of pulmonary hypertension, based on the results of the Framingham Heart Study with a healthy reference group (11). However, due to the limited data regarding the correlation of these cutoff values to the pathological conditions at that time (year 2012), the same authors emphasized that the evidence was limited for using these data as cutoff values [11]. In a meta-analysis, published 2 years later, including 2134 subjects, the sensitivity of the summary estimates for mPAD measurement in the diagnosis of pulmonary hypertension was 0.79 (95\% CI 0.72 0.84 ), and specificity, 0.83 (95\% CI $0.75-0.89$ ), respectively, [34].

We applied a cutoff level of 7 for the Warrick score for a CT-based diagnosis of pulmonary involvement as previously suggested [19]. This level corresponded to the best compromise between sensitivity $(0.60)$ and specificity $(0.83)$, with a positive predictive value of 0.82 [19].

\section{Study limitations}

First, the total number of patients in this single-center study is not sufficient for a proper prevalence study, and the results should be interpreted cautiously. However, scleroderma is a rare disease, and our clinical cohort is, indeed, to date, the largest sample in literature. Second, we did not perform a full-night PSG, and type 3-level HSAT might have resulted in an underestimation of OSA diagnosis due to overestimation of total sleep time. However, a cutoff level of AHI 15 events/h has been shown to be reliable for OSA diagnosis in the
Table 3 Variables associated with enlarged mPAD in adults with scleroderma in a logistic regression analysis

\begin{tabular}{|c|c|c|c|}
\hline & Odds ratio & $95 \%$ confidence interval & $p$ value \\
\hline \multicolumn{4}{|l|}{ Univariate } \\
\hline Age & 1.04 & $0.98-1.09$ & 0.191 \\
\hline BMI & 1.15 & $1.01-1.30$ & 0.036 \\
\hline Obesity & 2.54 & $0.79-8.19$ & 0.119 \\
\hline Disease duration (years) & 1.01 & $0.93-1.11$ & 0.778 \\
\hline Hypertension & 0.59 & $0.11-3.06$ & 0.528 \\
\hline $\mathrm{DL}_{\mathrm{CO}}(\%)$ & 0.97 & $0.93-1.00$ & 0.083 \\
\hline $\mathrm{DL}_{\mathrm{CO}}<80 \%$ & 2.13 & $0.41-11.06$ & 0.369 \\
\hline Warrick score & 1.01 & $0.96-1.07$ & 0.671 \\
\hline Pulmonary involvement (Warrick score $\geq 7$ ) & 0.44 & $0.14-1.40$ & 0.164 \\
\hline $\mathrm{AHI} \geq 5 / \mathrm{h}$ & 2.32 & $0.57-9.32$ & 0.239 \\
\hline OSA $(\mathrm{AHI} \geq 15 / \mathrm{h})$ & 6.00 & $1.75-20.55$ & 0.004 \\
\hline AHI & 1.07 & $1.02-1.13$ & 0.006 \\
\hline ODI & 1.09 & $1.03-1.16$ & 0.004 \\
\hline Minimum $\mathrm{SpO}_{2}(\%)$ & 0.89 & $0.82-0.97$ & 0.010 \\
\hline $\mathrm{SpO}_{2}<\mathrm{T} 90(\%)$ & 1.05 & $1.00-1.11$ & 0.065 \\
\hline \multicolumn{4}{|l|}{ Multivariate } \\
\hline Age & 1.01 & $0.94-1.07$ & 0.878 \\
\hline BMI & 1.07 & $0.93-1.24$ & 0.360 \\
\hline Pulmonary involvement (Warrick score $\geq 7$ ) & 0.37 & $0.10-1.39$ & 0.551 \\
\hline OSA $(\mathrm{AHI} \geq 15 / \mathrm{h})$ & 4.70 & $1.06-20.88$ & 0.042 \\
\hline
\end{tabular}

$A H I$, apnea-hypopnea index; $B M I$, body mass index; $D L_{C O}$, diffusing capacity of lung for carbon-monoxide; $E S S$, Epworth Sleepiness Scale; $m P A D$, main pulmonary artery diameter; $O D I$, oxygen desaturation index; $O S A$, obstructive sleep apnea; $\mathrm{SpO}_{2}$, oxyhemoglobin saturation; T90, time spent below $90 \%$ oxyhemoglobin saturation 
Fig. 3 a Correlation between main pulmonary artery diameter and apnea-hypopnea-index. b Correlation between main pulmonary artery diameter and oxygen desaturation index
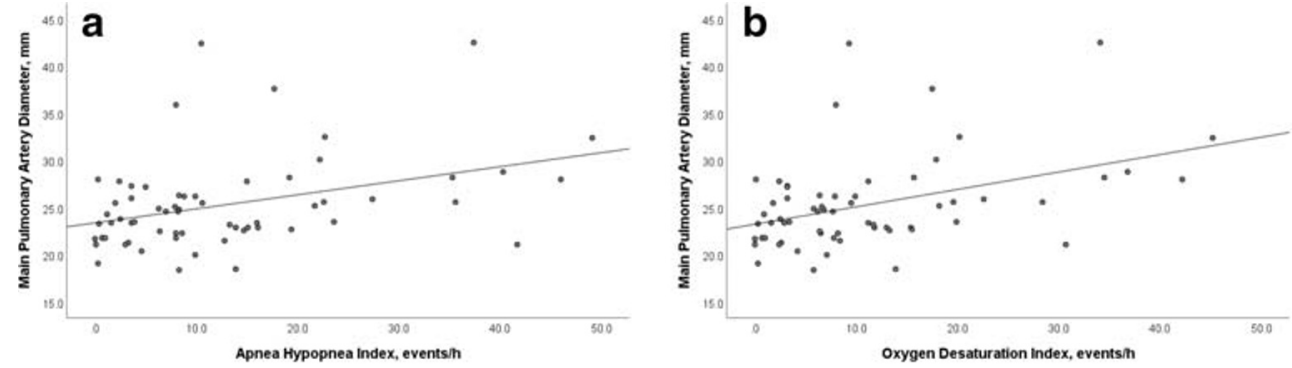

absence of OSA-related symptoms with this kind of diagnostic equipment [35]. Third, we did not perform right heart catheterization, which is the gold standard for the establishment of pulmonary hypertension diagnosis [33]. However, its risks and disadvantages have also been discussed [8]. Chest CT is routinely conducted for investigation of pulmonary involvement, and mPAD may be used in combination with echocardiography for further consideration of right heart catheterization in selected cases. Finally, a prospective follow-up study to evaluate the clinical significance of the used cutoff values for mPAD with regard to reproducibility as well as changes in response to CPAP treatment in the OSA subgroup could give better insights for the mechanisms involved in the development of pulmonary hypertension in patients with scleroderma.

\section{Conclusions}

We conclude that OSA was associated with risk for pulmonary hypertension independent of pulmonary involvement in this cohort. Whether or not the treatment of concomitant OSA in patients with scleroderma reduces this risk needs to be further evaluated.

Acknowledgments The authors thank Vivisol Turkey for supplying the NOX-T3 devices used in the study.

Authors' contributions Conception and design: TY, YP. Analysis and interpretation: TY, BB, SK, HD, YY. Drafting the manuscript for important intellectual content: TY, BB, YP. All authors approved this manuscript in its final form.

Funding Information Open access funding provided by University of Gothenburg.

\section{Compliance with ethical standards}

The study protocol conforms to the ethical guidelines of the 1975 Declaration of Helsinki as reflected in a priori approval by the Ethics Committee of the Medical Faculty of the Marmara University, Istanbul (approval no.: 09.2016.208). All patients provided written informed consent.
Conflict of interest YP received institutional grants from ResMed outside the current work. All other authors declare that they have no conflict of interest.

Open Access This article is licensed under a Creative Commons Attribution 4.0 International License, which permits use, sharing, adaptation, distribution and reproduction in any medium or format, as long as you give appropriate credit to the original author(s) and the source, provide a link to the Creative Commons licence, and indicate if changes were made. The images or other third party material in this article are included in the article's Creative Commons licence, unless indicated otherwise in a credit line to the material. If material is not included in the article's Creative Commons licence and your intended use is not permitted by statutory regulation or exceeds the permitted use, you will need to obtain permission directly from the copyright holder. To view a copy of this licence, visit http://creativecommons.org/licenses/by/4.0/.

\section{References}

1. Elhai M, Avouac J, Kahan A, Allanore Y (2015) Systemic sclerosis: recent insights. Joint Bone Spine 82:148-153

2. Bussone G, Mouthon L (2011) Interstitial lung disease in systemic sclerosis. Autoimmun Rev 10:248-255

3. Tashkin DP, Elashoff R, Clements PJ, Goldin J, Roth MD, Furst DE, Arriola E, Silver R, Strange C, Bolster M, Seibold JR, Riley DJ, Hsu VM, Varga J, Schraufnagel DE, Theodore A, Simms R, Wise R, Wigley F, White B, Steen V, Read C, Mayes M, Parsley E, Mubarak K, Connolly MK, Golden J, Olman M, Fessler B, Rothfield N, Metersky M (2006) Cyclophosphamide versus placebo in scleroderma lung disease. N Engl J Med 354:2655-2666

4. Guilleminault C (1985) Obstructive sleep apnea: the clinical syndrome and historical perspective. Med Clin North Am 69:11871203

5. Arter JL, Chi DS, M G, Fitzgerald SM, Guha B, Krishnaswamy G (2004) Obstructive sleep apnea, inflammation, and cardiopulmonary disease. Front Biosci 9:2892-2900

6. Pihtili A, Bingol Z, Kiyan E, Cuhadaroglu C, Issever H, Gulbaran Z (2013) Obstructive sleep apnea is common in patients with interstitial lung disease. Sleep Breath Schlaf \& Atmung 17:1281-1288

7. Simonneau G, Montani D, Celermajer DS, Denton CP, Gatzoulis MA, Krowka M, Williams PG, Souza R (2019) Haemodynamic definitions and updated clinical classification of pulmonary hypertension. Eur Respir J 53

8. Hoeper MM, Lee SH, Voswinckel R, Palazzini M, Jais X, Marinelli A, Barst RJ, Ghofrani HA, Jing ZC, Opitz C, Seyfarth HJ, Halank M, McLaughlin V, Oudiz RJ, Ewert R, Wilkens H, Kluge S, Bremer HC, Baroke E, Rubin LJ (2006) Complications of right heart 
catheterization procedures in patients with pulmonary hypertension in experienced centers. J Am Coll Cardiol 48:2546-2552

9. Bossone E, D'Andrea A, D'Alto M, Citro R, Argiento P, Ferrara F, Cittadini A, Rubenfire M, Naeije R (2013) Echocardiography in pulmonary arterial hypertension: from diagnosis to prognosis. $\mathrm{J}$ Am Soc Echocardiogr 26:1-14

10. Janda S, Shahidi N, Gin K, Swiston J (2011) Diagnostic accuracy of echocardiography for pulmonary hypertension: a systematic review and meta-analysis. Heart 97:612-622

11. Truong QA, Massaro JM, Rogers IS, Mahabadi AA, Kriegel MF, Fox CS, O’Donnell CJ, Hoffmann U (2012) Reference values for normal pulmonary artery dimensions by noncontrast cardiac computed tomography: the Framingham Heart Study. Circ Cardiovasc Imaging 5:147-154

12. (1998) Clinical guidelines on the identification, evaluation, and treatment of overweight and obesity in adults-the evidence report. National Institutes of Health. Obes Res 6(Suppl 2):51S-209S

13. LeRoy EC, Black C, Fleischmajer R, Jablonska S, Krieg T, Medsger TA Jr, Rowell N, Wollheim F (1988) Scleroderma (systemic sclerosis): classification, subsets and pathogenesis. J Rheumatol 15:202-205

14. (1995) Standardization of spirometry, 1994 Update. American Thoracic Society. Am J Respir Crit Care Med 152:1107-1136

15. Miller MR, Crapo R, Hankinson J, Brusasco V, Burgos F, Casaburi R, Coates A, Enright P, van der Grinten CP, Gustafsson P, Jensen R, Johnson DC, MacIntyre N, McKay R, Navajas D, Pedersen OF, Pellegrino R, Viegi G, Wanger J (2005) General considerations for lung function testing. Eur Respir J 26:153-161

16. Cotes JE, Chinn DJ, Quanjer PH, Roca J, Yernault JC (1993) Standardization of the measurement of transfer factor (diffusing capacity). Report Working Party Standardization of Lung Function Tests, European Community for Steel and Coal. Official Statement of the European Respiratory Society. Eur Respir J Suppl 16:41-52

17. Enright PL, Sherrill DL (1998) Reference equations for the sixminute walk in healthy adults. Am J Respir Crit Care Med 158: 1384-1387

18. Warrick JH, Bhalla M, Schabel SI, Silver RM (1991) High resolution computed tomography in early scleroderma lung disease. $\mathrm{J}$ Rheumatol 18:1520-1528

19. Diot E, Boissinot E, Asquier E, Guilmot JL, Lemarie E, Valat C, Diot P (1998) Relationship between abnormalities on highresolution $\mathrm{CT}$ and pulmonary function in systemic sclerosis. Chest 114:1623-1629

20. Johns MW (1991) A new method for measuring daytime sleepiness: the Epworth sleepiness scale. Sleep 14:540-545

21. Izci B, Ardic S, Firat H, Sahin A, Altinors M, Karacan I (2008) Reliability and validity studies of the Turkish version of the Epworth Sleepiness Scale. Sleep Breath Schlaf \& Atmung 12: 161-168

22. Hayley AC, Williams LJ, Berk M, Kennedy GA, Jacka FN, Pasco JA (2013) The relationship between excessive daytime sleepiness and depressive and anxiety disorders in women. Aust $\mathrm{N} \mathrm{Z} \mathrm{J}$ Psychiatr 47:772-778

23. Kapur VK, Auckley DH, Chowdhuri S, Kuhlmann DC, Mehra R, Ramar K, Harrod CG (2017) Clinical practice guideline for diagnostic testing for adult obstructive sleep apnea: an American Academy of sleep medicine clinical practice guideline. J Clin Sleep Med 13:479-504

24. Sateia MJ (2014) International classification of sleep disorders-third edition: highlights and modifications. Chest 146:1387-1394

25. Frech T, Hays RD, Maranian P, Clements PJ, Furst DE, Khanna D (2011) Prevalence and correlates of sleep disturbance in systemic sclerosis-results from the UCLA scleroderma quality of life study. Rheumatology (Oxford, England) 50:1280-1287

26. Prado GF, Allen RP, Trevisani VM, Toscano VG, Earley CJ (2002) Sleep disruption in systemic sclerosis (scleroderma) patients: clinical and polysomnographic findings. Sleep Med 3:341-345

27. Milette K, Hudson M, Korner A, Baron M, Thombs BD (2013) Sleep disturbances in systemic sclerosis: evidence for the role of gastrointestinal symptoms, pain and pruritus. Rheumatology (Oxford, England) 52:1715-1720

28. Mermigkis C, Chapman J, Golish J, Mermigkis D, Budur K, Kopanakis A, Polychronopoulos V, Burgess R, Foldvary-Schaefer $N$ (2007) Sleep-related breathing disorders in patients with idiopathic pulmonary fibrosis. Lung 185:173-178

29. Lancaster LH, Mason WR, Parnell JA, Rice TW, Loyd JE, Milstone AP, Collard HR, Malow BA (2009) Obstructive sleep apnea is common in idiopathic pulmonary fibrosis. Chest 136:772-778

30. Kohno T, Kataoka M, Kawakami T, Fukuoka R, Tamura Y, Kimura M, Takei M, Maekawa Y, Sano M, Fukuda K (2017) Moderate-tosevere obstructive sleep apnea is associated with subclinical myocardial injury and impaired hemodynamics in pulmonary hypertension patients. Sleep Med 30:121-127

31. Laks L, Lehrhaft B, Grunstein RR, Sullivan CE (1995) Pulmonary hypertension in obstructive sleep apnoea. Eur Respir J 8:537-541

32. Dobrowolski P, Florczak E, Klisiewicz A, Prejbisz A, Rybicka J, Sliwinski P, Januszewicz A, Hoffman P (2016) Pulmonary artery dilation indicates severe obstructive sleep apnea in patients with resistant hypertension: the Resist-POL Study. Pol Arch Med Wewn 126:222-229

33. Kiely DG, Elliot CA, Sabroe I, Condliffe R (2013) Pulmonary hypertension: diagnosis and management. BMJ 346:f2028

34. Shen Y, Wan C, Tian P, Wu Y, Li X, Yang T, An J, Wang T, Chen L, Wen F (2014) CT-base pulmonary artery measurement in the detection of pulmonary hypertension: a meta-analysis and systematic review. Medicine 93:e256

35. Cairns A, Wickwire E, Schaefer E, Nyanjom D (2014) A pilot validation study for the NOX T3(TM) portable monitor for the detection of OSA. Sleep Breath Schlaf \& Atmung 18:609-614

Publisher's note Springer Nature remains neutral with regard to jurisdictional claims in published maps and institutional affiliations. 